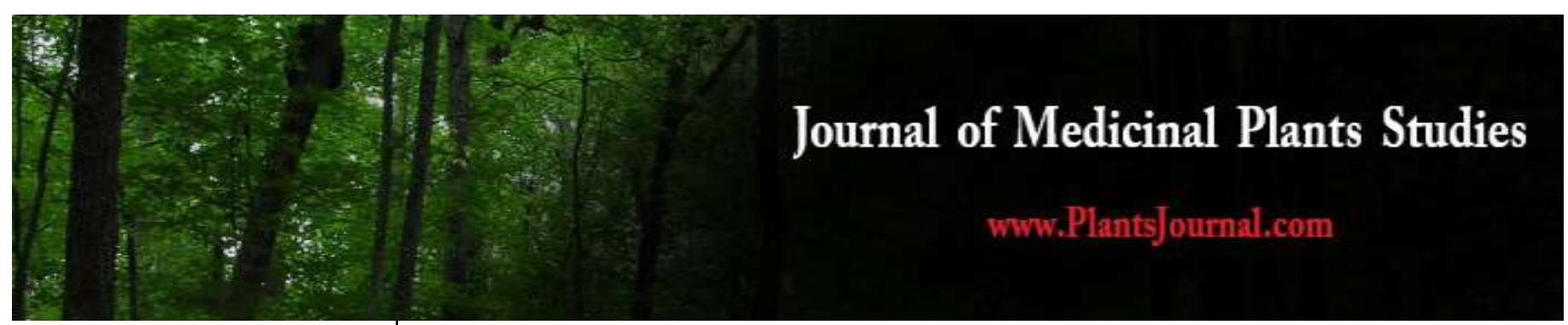

ISSN (E): 2320-3862 ISSN (P): 2394-0530

www.plantsjournal.com JMPS 2022; 10(1): 12-16 (C) 2022 JMPS

Received: 20-10-2021

Accepted: 04-12-2021

Mona Alhasien Abdlgader Ahmed Department of Chemistry, Faculty of Education, University of Khartoum, Sudan

\section{Abuelgasim Abbaker} Abedelrasoul Mohammed

Department of Chemistry, Faculty of Education, University of Khartoum, Sudan

Khogali Elnur Ahmed Ishag Department of Food Science and Technology, Faculty of Agriculture, University of Khartoum, Sudan
Corresponding Author:

Mona Alhasien Abdlgader Ahmed Department of Chemistry,

Faculty of Education, University of Khartoum, Sudan

\section{Identification and determination of organic acids in some selected medicinal plants grown in Sudan.}

\author{
Mona Alhasien Abdlgader Ahmed, Abuelgasim Abbaker Abedelrasoul \\ Mohammed and Khogali Elnur Ahmed Ishag
}

DOI: https://doi.org/10.22271/plants.2022.v10.i1a.1355

\section{Abstract}

The aim of this study is to determine acetic acid, ascorbic acid, citric acid, oxalic acid and tartaric acid in Sudanese medicinal plants (Adansonia digitata fruit pulp, Hibiscus sabdriffa calyx, Hyphaene thebaica fruit pulp and Tamarindus indica pulp) by RP-HPLC-UV method. The method used is based on using an ultrasonic bath for extracting organic acids. The investigation showed that concentrations of ascorbic acid (1.65 mg/g \pm 0.099$)$, citric acid $(56.00 \mathrm{mg} / \mathrm{g} \pm 0.22)$, and oxalic acid $(1.35 \mathrm{mg} / \mathrm{g} \pm 0.039)$. The highest values for Adansonia digitata compared to other plants in this study. Tamarindus indica showed higher concentration of tartaric acid $(23.75 \mathrm{mg} / \mathrm{g} \pm 0.0 .36)$ compare to other plants, and Hypheane thebaica showed lower concentration of ascorbic acid $(0.02 \mathrm{mg} / \mathrm{g} \pm 0.242)$. These Sudanese medicinal plants are recommended as a promising source for the above mentioned organic acids; could contribute considerably towards meeting human nutritional requirements for normal growth and protection against several diseases.

Keywords: Organic acids, Sudanese medicinal plants, ultrasonic extraction, RP-HPLC-UV

\section{Introduction}

Organic acids play an important role in plants as flavour, colour, aroma, stability and microbiological control of the products, (Nour et al. 2010) ${ }^{[13]}$. Also, the acids used to enhance beverage flavours are citric, tartaric, fumaric and phosphoric acids. Citric acid is the most widely used acid while tartaric acid is an important natural compound of fruits that are used along with fumaric acid in fruit-flavoured drinks, (Shui and Leong, 2002) ${ }^{[16]}$. Ascorbic acid (vitamin C) known for its antioxidant and equally important in immune functions and improves the absorption of non-heme iron, (Danbature et al. 2015) ${ }^{[7]}$.

Adansonia digitata, Hibiscus sabdariffa, Hyphaene thebaica and Tamarindus indica are known in the Sudanese communities as Tabaldi, Karkadeh, Doum and Aradib respectively, these plants having great interest, and reported to have good nutritional value and medicinal properties, which include antioxidant, (Meda et al. (2008) ${ }^{[10]}$; Sirag et al. (2014) ${ }^{[17]}$; Aboshora 2 et al. (2014) ${ }^{[1,2]}$, antibacterial, antirheumatic, anticancer (Abou Ellalla, 2009) ${ }^{[3]}$ and antimalarial activity, (Menezes et al. 2016) ${ }^{[11]}$. These plants have characteristic tastes and flavour which make them acceptable in the preparation of cold and hot drinks in Sudan; also they have recently become a popular ingredient in homemade ice creams.

There are some studies on the organic acids present in these plants collected from Southern and western African regions. Kamatou et al. 2011 reported that the fruits of Adansonia digitata are excellent antioxidant. Danbature et al. $2015^{[7]}$ determined ascorbic acid in Adansonia digitata pulp collected from Gombe, Nigeria using the spectrophotometric method. While Ibrahima et al. (2013) ${ }^{[9]}$ determined ascorbic acid in the pulp of Adansonia digitata by titration method. Whereas Nour et al. (1980) ${ }^{[12]}$ determined ascorbic acid in Adansonia digitata pulp collected from Khartoum (Sudan) by titration method. Biri et al. (2015) determined oxalic acid in Hibiscus sabdriffa calyxes collected from Buchi, Nigeria; using titration method, and also they reported that regular consumption of Karkadeh drink might lead to the formation of an insoluble precipitate of minerals such as calcium which may accumulate in the kidney to form kidney stones. Ibrahim et al. (2015) determined citric acid, oxalic acid and tartaric acid in Hibiscus sabdriffa calyxes collected from Baghdad (Iraq). 
Aboshora et al. (2014) ${ }^{[1,2]}$ determined ascorbic acid in Hypheane thebaica collected from Elgazira Aba (Sudan).

The objective of this study is identification and determination of ascorbic acid, citric acid, oxalic acid and tartaric acid in Adansonia digitata, Hibiscus sabdariffa, Hyphaene thebaica, and Tamarindus indica available for Sudanese consumers, in Khartoum state (Sudan), by reverse phase high performance liquid chromatography (RP-HPLC) with ultraviolet detector using ultrasonic bath for extracting organic acids.

\section{Materials and Methods \\ Plant materials}

The edible parts of plant materials (Tabaldi, Doum, Tamarinds and Karkadeh calyxes) were purchased from local markets (Khartoum, Sudan). The materials of plants were identified and authenticated by the herbarium unit (National Center for Research, Sudan).

\section{Chemicals and reagents}

Ethanol (AR), potassium dihydrogen phosphate, and phosphoric acid were obtained from s. d fine- CHIME Limited (India). Standards (ascorbic acid, acetic acid, citric acid, oxalic acid, and tartaric acid) were from Sigma Aldrich (St. Louis, MO, USA). All chemicals were analytical grade, and the HPLC-grade water was used throughout the study.

\section{Samples preparation}

The pulp of Tabaldi, Doum and Tamarinds and were removed from the seeds. The samples (Tabaldi, Karkadeh, Doum and Tamarinds) were cleaned, and they were allowed to dry in dark for two weeks. The samples were ground to a powder using food grinder, then pass through sieve mesh $(0.08 \mathrm{~mm})$, and then kept in labelled glass jars and stored in refrigerator.

\section{Extraction of organic acid}

One gram of each sample was accurately weighed and placed in glass beakers, then $10 \mathrm{ml}$ of ethanol $(70 \% \mathrm{v} / \mathrm{v})$ were added. The mixture was homogenized by shaker (REMI RS-12India) for $5 \mathrm{~min}$ at $70 \mathrm{rpm}$. Then the glass beaker was placed in an ultrasonic bath (BANDELIN electronic- Germany) for $1 \mathrm{~h}$ at room temperature $\left(25^{\circ} \mathrm{C}\right)$, and then the mixture was allowed to stand for $5 \mathrm{~min}$ and centrifuged (HettichGermany) at $4000 \mathrm{rpm}$ for $15 \mathrm{~min}$. The extract was filtered through filter paper; and then dried at room temperature; all extracts were stored in clean containers and kept in the freezer for analysis.

\section{Analysis by HPLC}

The separation of acetic acid, ascorbic acid, citric acid, oxalic acid and tartaric acid in the plants extracts were carried out on HPLC with UV detector (Shimadzu- Japan), as described by Reuter (2015) ${ }^{[15]}$, with some modification.

\section{Experimental conditions}

The chromatographic conditions applied were as follows: The separation was achieved by reverse phase RP column 18 $(\mathrm{C} 18$ : $250.0 \times 4.6 \mathrm{~mm}, 5.0 \mu \mathrm{m})$. The mobile phase consisted of $25 \mathrm{mM}$ potassium dihydrogenphosphate (KH2PO4) adjusted to $\mathrm{pH}=2.40$ with $1 \%(\mathrm{w} / \mathrm{v})$ of phosphoric acid (H3PO4) (buffer), applied in isocratic elution for $30 \mathrm{~min}$. The flow rate was adjusted at $1.5 \mathrm{ml} / \mathrm{min}$ ( $\sim 3000 \mathrm{psi} ; 200 \mathrm{bar})$. The detection was measured at wavelength $\lambda=210.0 \mathrm{~nm}$ by UV detector. The sample volume was injected $20 \mu \mathrm{l}$, and the oven temperature at $30.0{ }^{\circ} \mathrm{C}$.

\section{Preparation of standard solutions}

Stock solutions (1000 ppm) of each organic acid in this study were prepared in $0.1 \%(\mathrm{w} / \mathrm{v})$ phosphoric acid solution. HPLCgrade water was used for both solvent and diluent.

\section{Method validation}

The validation study for organic acids using RP-HPLC-UV was performed under conditions as linearity, precision, accuracy, retention time (Rt), correlation coefficient (r2), relative standard deviation (RSD) and limit of detection (LOD). Quantification was performed with five point external calibration curves. Precision was determined as repeatability (three successive injections). Accuracy of the method was tested by performing the mean of the percentage recovery was $101 \%, 96.7 \%, 101 \%, 101.6 \%$ and $100 \%$ for acetic acid, ascorbic acid, citric acid, oxalic acid and tartaric acid respectively. Table 1 shows the validation of analytical method obtained from calibration curves of organic acids analysed by RP-HPLC-UV. The chromatogram of standard mixture of organic acids is shown Figure 1.

Table 1: Validation of analytical method of five organic acids standards by RP-HPLC-UV

\begin{tabular}{|c|c|c|c|c|c|c|}
\hline Organic acid & Rt & Concentration range & Linear equation & r2 & RSD\% n=5 & LOD \\
\hline Acetic acid & 6.682 & $24-120$ & $\mathrm{Y}=17772 \mathrm{x}+370.5$ & 0.997 & 1.7 & 0.065 \\
\hline Ascorbic acid & 5.818 & $8-40$ & $\mathrm{Y}=90476 \mathrm{x}-1959.6$ & 0.998 & 1.7 & 0.049 \\
\hline Citric acid & 10.906 & $24-120$ & $\mathrm{Y}=35308 \mathrm{x}+2437.2$ & 0.999 & 1.08 & 0.055 \\
\hline Oxalic acid & 3.240 & $8-40$ & $\mathrm{Y}=105120 \mathrm{x}+103845$ & 0.995 & 1.4 & 0.079 \\
\hline Tartaric acid & 3.734 & $24-120$ & $\mathrm{Y}=59842 \mathrm{x}+10341$ & 0.996 & 1.6 & 0.094 \\
\hline
\end{tabular}

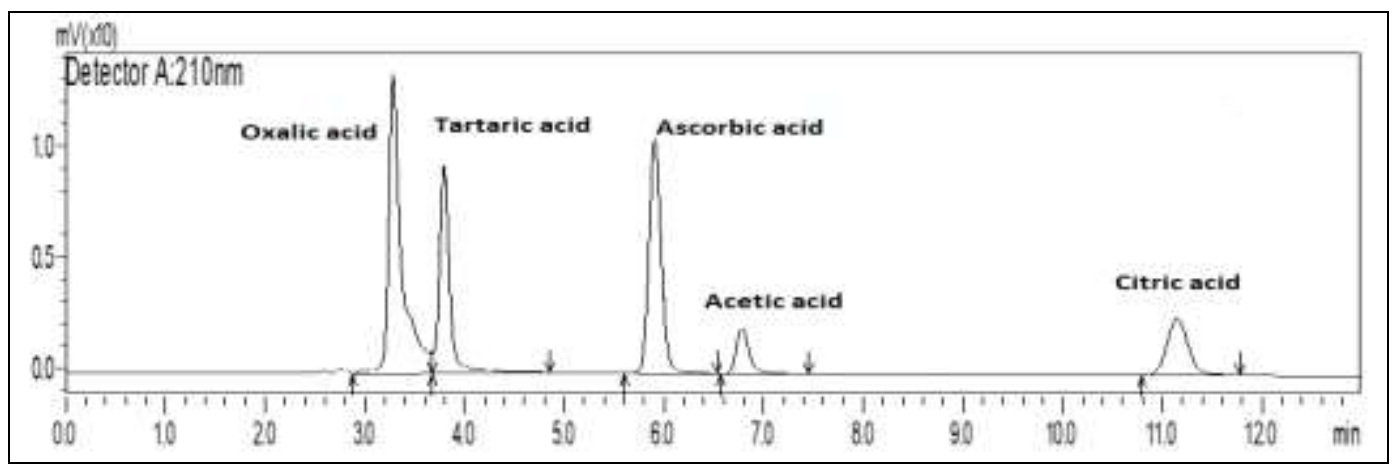

Fig 1: Chromatogram of standard mixture of organic acids; UV at $210 \mathrm{~nm}$ 


\section{Results and Discussion}

Adansonia digitata, Hibiscus sabdariffa, Hyphaene thebaica and Tamarindus indica are four medicinal plants greatly appreciated in Sudan and many Africa countries. The concentrations of organic acids $(\mathrm{mg} / \mathrm{g})$ are presented in Table 2 , and chromatograms of the organic acids are shown in Figures 2, 3, 4 and 5 .

Table 2: Concentration of organic acids in Sudanese medicinal plants (mg/g)

\begin{tabular}{|c|c|c|c|c|c|}
\hline \multirow{2}{*}{ Plant materials } & \multicolumn{5}{|c|}{ Concentration $(\mathbf{m g} / \mathbf{g}) \pm$ SD$^{*}$} \\
\cline { 2 - 6 } & Ascorbic acid & Acetic acid & Citric acid & Oxalic acid & Tartaric acid \\
\hline Adansonia digitata & $1.65 \pm 0.099$ & nd & $56.00 \pm 0.22$ & $1.35 \pm 0.039$ & $0.574 \pm 0.062$ \\
\hline Hibiscus sabdariffa & $0.273 \pm 0.027$ & nd & $0.94 \pm 0.042$ & $0.965 \pm 0.086$ & $8.43 \pm 0.008$ \\
\hline Hyphaene thebaica & $0.02 \pm 0.242$ & nd & $8.75 \pm 0.082$ & $0.90 \pm 0.063$ & $0.952 \pm 0.052$ \\
\hline Tamarindus indica & $0.115 \pm 0.204$ & nd & $0.502 \pm 0.32$ & $0.69 \pm 0.084$ & $23.75 \pm 0.036$ \\
\hline
\end{tabular}

*Values as: mean of concentration $\mathrm{mg} / \mathrm{g} \pm$ Standard Deviation $\mathrm{SD}(\mathrm{n}=5)$.

* nd: not detected.

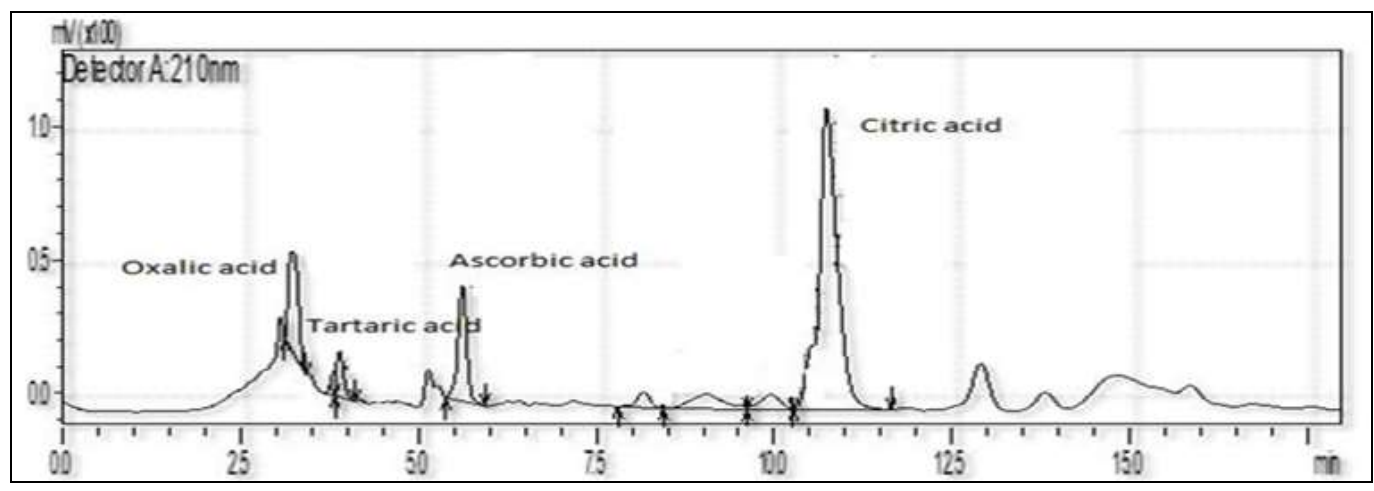

Fig 2: Chromatogram of organic acids in Adansonia digitate

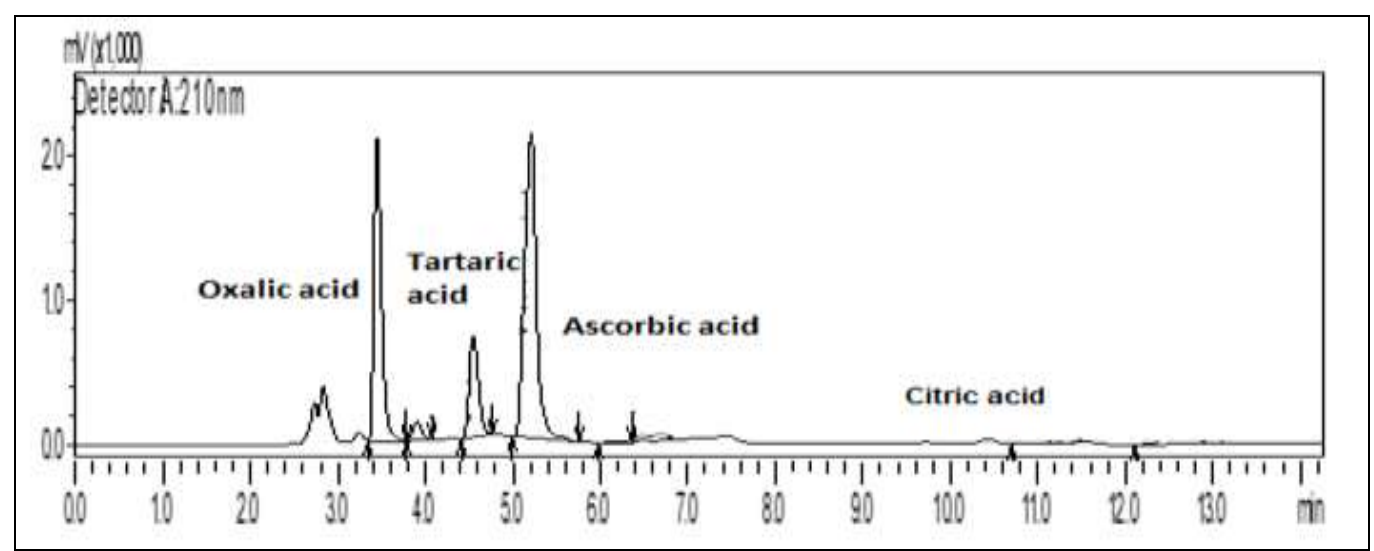

Fig 3: Chromatogram of organic acids in Hibiscus sabdriffa

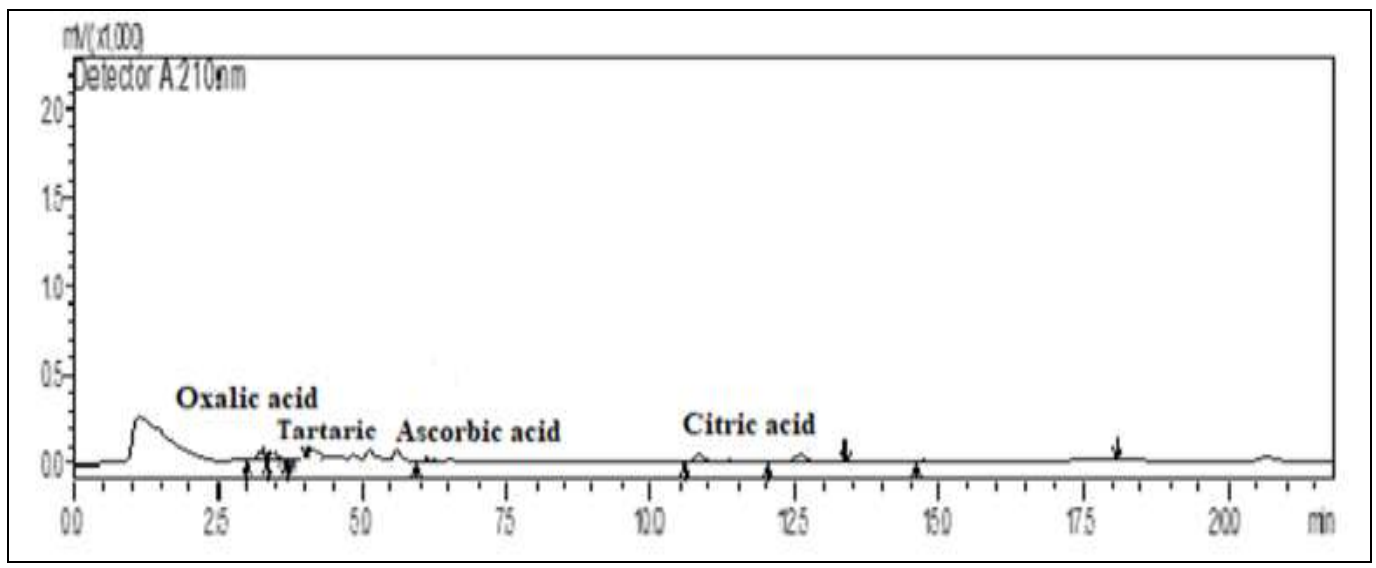

Fig 4: Chromatogram of organic acids in Hyphaene thebaica 


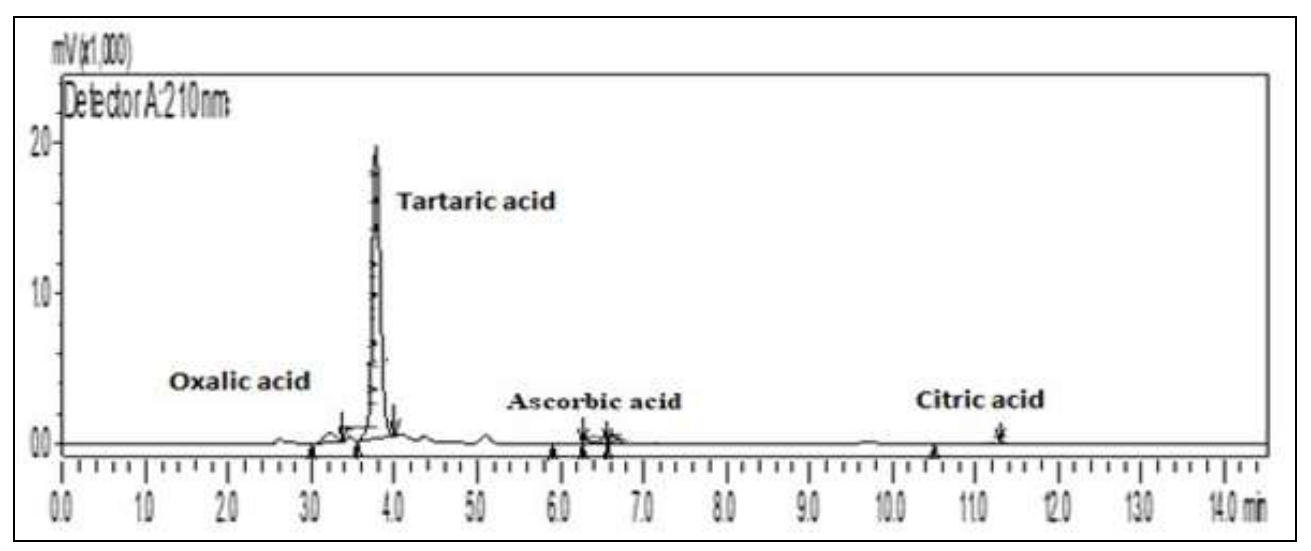

Fig 5: Chromatogram of organic acids in Tamarindus in

Citric acid has highest concentration of organic acids (56 $\mathrm{mg} / \mathrm{g} \pm 0.22$ ) was found in Adansonia digitata. The high concentration of ascorbic acid (1.65 mg/g \pm 0.099$)$ in Adansonia digitata whiles the lowest concentration of ascorbic acid $(0.02 \mathrm{mg} / \mathrm{g} \pm 0.242)$ was found in Hyphaene thebaica. Adansonia digitata has more ascorbic acid, citric acid and oxalic acid (1.35 mg/g \pm 0.039$)$ compare to other plants in this study. Tamarindus indica has highest concentration of tartaric acid $(23.75 \mathrm{mg} / \mathrm{g} \pm 0.0 .36)$ than other plants, while Adansonia digitata have lower concentration of tartaric acid $(0.574 \mathrm{mg} / \mathrm{g} \pm 0.062)$.

These results in comparison with other results shown in Table 3. Ascorbic acid content in Adansonia digitata was found higher than Ibrahima et al. (2013) ${ }^{[9]}$ and Danbature et al.
(2015) [7], and smaller than Nour et al., (1980) ${ }^{[12]}$ and Omar et al. (2020) ${ }^{[14]}$. Ascorbic acid of Hyphaene thebaica was moderated higher than Aboshora et al. (2017), and less than Omar et al. (2020) ${ }^{[14]}$. The values of organic acids in Hibiscus sabdariffa were higher than Ibrahim et al. (2015). In this study organic acid was determined in medicinal plants by different method from other reports whereas the other authors as Omar et al. (2020) ${ }^{[14]}$ analyzed by high performance liquid chromatography with photodiode array detector (HPLCPDA), and Bressiani et al. (2021) ${ }^{[6]}$ were quantified ascorbic acid by the titration method using 2.6dichlorophenolindophenol. Thus the observed differences in organic acids concentration could be attributed to the type of extraction, analytical methods and conditions used.

Table 3: Comparison of organic acids content with previous studies

\begin{tabular}{|c|c|c|c|c|c|c|}
\hline & Ascorbic acid & Citric acid & Oxalic acid & Tartaric acid & Reference & Method \\
\hline \multirow[t]{5}{*}{ Adansonia digitata } & $291.92 \mathrm{mg} / 100 \mathrm{~g}$ & \begin{tabular}{|l|}
- \\
\end{tabular} & - & - & Danbature et al., (2015) ${ }^{[7]}$ & UV-Vis Spectrophotometry \\
\hline & $67 \mathrm{mg} / 100 \mathrm{~g}$ & - & - & - & Ibrahima et al., (2013) ${ }^{[9]}$ & Titration \\
\hline & $300 \mathrm{mg} / 100 \mathrm{~g}$ & - & - & - & Nour et al., $(1980)^{[12]}$ & Titration \\
\hline & $302.11 \mathrm{mg} / 100 \mathrm{~g}$ & - & - & - & Omar et al., (2020) ${ }^{[14]}$ & HPLC-PDA \\
\hline & $175 \mathrm{mg} / 100 \mathrm{~g}$ & - & - & - & Stadlmayr et al., (2020) ${ }^{[18]}$ & Titration \\
\hline \multirow[t]{4}{*}{ Hibiscus sabdriffa } & - & - & $4.8 \%$ & - & Biri et al., (2015) & Titration \\
\hline & - & $126.90 \mu \mathrm{g} / \mathrm{g}$ & $268.52 \mu \mathrm{g} / \mathrm{g}$ & $342.50 \mu \mathrm{g} / \mathrm{g}$ & Ibrahim et al., (2015) & RP-HPLC-UV \\
\hline & $257.6 \mathrm{mg} / 100 \mathrm{~g}$ & - & - & - & Omar et al., $(2020)^{[14]}$ & HPLC-PDA \\
\hline & $16.9 \mathrm{mg} / 100 \mathrm{~g}$ & - & - & - & Ahmed et al., (2019) ${ }^{[4]}$ & UV-Vis-Spectrophotometry \\
\hline \multirow[t]{2}{*}{ Hyphaene thebaica } & $1.12 \mathrm{mg} / 100 \mathrm{~g}$ & - & - & - & Aboshora et al., (2014) ${ }^{[1,2]}$ & RP-HPLC-UV \\
\hline & $225.2 \mathrm{mg} / 100 \mathrm{~g}$ & & & & Omar et al., $(2020)^{[14]}$ & HPLC-PDA \\
\hline \multirow[t]{3}{*}{ Tamarindus indica } & $62.31-58.92 \mathrm{mg} / 100 \mathrm{~g}$ & - & - & - & Bressiani et al., (2021) ${ }^{[6]}$ & Titration \\
\hline & 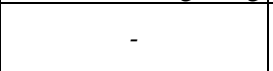 & - & $1.81 \mathrm{mg} / 100 \mathrm{~g}$ & $4.36 \mathrm{mg} / 100 \mathrm{~g}$ & Duan et al., (2020) ${ }^{[8]}$ & $\begin{array}{c}\text { UPLC (Ultra-performance liquid } \\
\text { chromatography) }\end{array}$ \\
\hline & $0.54-0.33 \mathrm{mg} / 100 \mathrm{~g}$ & - & - & - & Bhavani et al., (2021) ${ }^{[5]}$ & Titration \\
\hline
\end{tabular}

\section{Conclusion}

Organic acids contents were determined in four Sudanese medicinal plants (Adansonia digitata, Hibiscus sabdariffa, Hyphaene thebaica, and Tamarindus indica). The ascorbic, citric, oxalic and tartaric acids have been extracted by ultrasonic technique and qualitative and quantitative by RPHPLC-UV detector method.

Adansonia digitata pulp contained the high concentration of ascorbic acid, citric acid and oxalic acid compared to other plants used in the study. The most important property of that Adansonia digitata is the high value of ascorbic acid. This high concentration contributes to a stimulating effect on the human immune. Tartaric acid, oxalic acid and citric acid were higher concentrations than ascorbic acid in Hibiscus sabdariffa calyxes. Hyphaene thebaica pulp showed the lowest concentration of ascorbic acid to other plants in this study. Tamarindus indica pulp showed the highest concentration of tartaric acid compare to other plants.
It could be concluded that the medicinal plants are very much more nutritive and hygienic for the human body, and this method is suitable for the determination of organic acids in Sudanese medicinal plants. Other organic acids can be determined by the same method.

\section{References}

1. Aboshora W, Lianfu Z, Dahir M, Gasmalla MAA, Musa A, Omer E, et al. Physicochemical, Nutritional and Functional Properties of the Epicarp, Flesh and Pitted Sample of Doum Fruit (Hyphaene Thebaica). Journal of Food and Nutrition Research. 2014;2(4):180-186.

2. Aboshora W, Lianfu Z, Dahir M, Qingran M, Qingrui S, Jing L, et al. Effect of Extraction Method and Solvent Power on Polyphenol and Flavonoid Levels in Hyphaene Thebaica L Mart (Arecaceae) (Doum) Fruit, and it is Antioxidant and Antibacterial Activities. Tropical Journal of Pharmaceutical Research. 2014;13(12):2057-2063. 
3. Abou Elalla F. Antioxidant and Anticancer Activities of Doum Fruit Extract (Hyphaene thebaica). African Journal of Pure and Applied Chemistry. 2009;3(10):197201.

4. Ahmed AF, Satti MN, Eltahir HS. A Comparative Study on Some Major Constituents of Karkade (Hibiscus sabdariffa L. Roselle Plant). International Journal of Life science and Pharma Research. 2019;9(1):1-12.

5. Bhavani BPVSG, Nirmala G, Lakshmi K, Lakshmi J. Comparative evaluation study on the physicochemical composition of three different tamarind varieties. Journal of Pharmacognosy and Phytochemistry. 2021;10(1):6066.

6. Bressiani AP, Lima RG, Dusman E, Tonin TL. Cytotoxic and antioxidant activities of Tamarindus indica pulp extract from Brazil. Journal of Food Measurement and Characterization. 2021;15:2743-2749.

7. Danbature WL, Yirankinyuki FF, Magaji B, Ibrahim Z. Comparative Determination of Vitamin $C$ and Iron in Ten (10) Locally Consumed Fruits in Gombe State, Nigeria. International Journal of Advanced Research in Chemical Science. 2015;2(8):14-18.

8. Duan W, Huang Y, Xiao J, Zhang Y, Tang Y. Determination of free amino acids, organic acids, and nucleotides in 29 elegant spices. Food Science and Nutrition. 2020;8:3777-3792.

9. Ibrahima C, Didier M, Max R, Pascal D, Benjamin Y, Renaud B. Biochemical and Nutritional Properties of Baobab Pulp From Endemic Species of Madagascar and The African Mainland. African Journal of Agricultural Research. 2013;8(47):6046-6054.

10. Meda AL, Lamien CE, Compaoré MMY, Meda RNT, Kiendrebeogo M, Zeba B. Polyphenol Content And Antioxidant Activity Of Fourteen Wild Edible Fruits From Burkina Faso. Journal of Molecules. 2008;13:581594.

11. Menezes APP, Trevisan SCC, Barbalho SM, Guiguer EL. Tamarindus indica L.: A Plant with Multiple Medicinal Purposes. Journal of Pharmacognosy and Phytochemistry. 2016;5(3):50-54.

12. Nour A, Magboul I, Kheiri H. Chemical composition of baobab (Adansonia digitata L.). Food research Center. Trop. Si. 1980;22(4):44-48.

13. Nour V, Ion T, Ionica M. HPLC Organic Acid Analysis in Different Citrus Juices under Reversed Phase Conditions. Notulae Botanicae Horti Agrobotanici, ClujNapoca. 2010;38(1):44-48.

14. Omar MM, Abdealsiede MM, Alrasheid AA, Elbashir AA. Antioxidant, Antimicrobial Activities and HPLC Quantitative Analysis of Some Sudanese Medicinal Plants. International Journal of Food and Nutritional Science. 2020;8(1):1-8.

15. Reuter WM. Analysis of Organic Acids in Fruit Juices By HPLC and UV Detection. Application note liquid chromatography. PerkinElmer, Inc. Shelton, CT, 2015. www.perkinelmer.com

16. Shui G, Leong LP. Separation and Determination of Organic Acids and Phenolic Compounds in Fruit Juices and Drinks by High Performance Liquid Chromatography. Journal of Chromatography-Elsevier. 2002;977:89-96.

17. Sirag N, Elhadi M, Algaili AM, Hassan HM, Ohaj M. Determination of Total Phenolic Content and Antioxidant Activity Of Roselle (Hibiscus sabdariffa L.) Calyx Ethanolic Extract. Standard Research Journal of
Pharmacy and Pharmacology. 2014;1(2):034-039.

18. Stadlmayr B, Wanangwe J, Waruhiu C, Jamnadass R, Kehlenbeck K. Nutritional composition of baobab (Adansonia digitata L.) fruit pulp sampled at different geographical locations in Kenya. Journal of Food Composition and Analysis. 2020;94:103617. 